\title{
Correlation between anti-Müllerian hormone, age, and number of oocytes: A retrospective study in a Brazilian in vitro fertilization center
}

\author{
Isadora Ferreira Kozlowski ${ }^{1}$, Matheus Campos Carneiro ${ }^{2}$, Vinicius Bonato da Rosa ${ }^{3}$, Alessandro Schuffner ${ }^{3}$ \\ ${ }^{1}$ Faculdade de Medicina, Pontifícia Universidade Católica Curitiba, Paraná, Brazil \\ ${ }^{2}$ Faculdade de Medicina, Faculdade Evangélica Mackenzie, Curitiba, Paraná, Brazil \\ ${ }^{3}$ Conceber Centro de Medicina Reprodutiva, Curitiba, Paraná, Brazil
}

\begin{abstract}
Objective: Is the AMH level correlated with age and number of mature oocytes retrieved from stimulated cycles?

Methods: This descriptive, retrospective, observational study included the data of about 1500 patients submitted to Assisted Reproductive Technology treatments in a clinic in Brazil between July 2012 and April 2019. Patients not submitted to IVF and/or without AMH level records were excluded. The study included women with fertility issues aged 20-50 years submitted to IVF. A total of 733 patients were included. The patients were divided by age into three groups ( $\leq 35$ years old; $36-39$ years old; $\geq 40$ years old).

Results: The mean $\mathrm{AMH}$ concentration ranged from 2.65 to $1.35 \mathrm{ng} / \mathrm{mL}$ and was significantly different between the groups. The mean total number of retrieved oocytes ranged from 9.5 to 5.42 and was significantly different between the groups. The mean number of mature oocytes ranged from 7.14 to 4.58 . There was no significant difference in the number of mature oocytes between patients aged $36-39$ years and $\geq 40$ years. Negative correlations were observed between patient age and total number of retrieved oocytes $(-0.3354)$ and number of mature oocytes $(-0.2839)$. AMH was negatively correlated with age $(-0.3257)$, although positive correlations with total number of oocytes (0.6702) and number of mature oocytes (0.5770) were observed.

Conclusions: This is the largest study performed with Brazilian patients to correlate AMH levels, age, number of oocytes, and number of mature oocytes from controlled ovarian stimulation cycles. Our data showed that as age increases, AMH levels, number of retrieved oocytes, and number of mature oocytes decrease significantly. However, no significant difference in number of mature oocytes was observed when patients aged $36-39$ and $\geq 40$ years were compared. In addition, a positive correlation was found between serum AMH levels and total number of retrieved and mature oocytes from stimulated cycles.
\end{abstract}

Keywords: $\mathrm{AMH}$, aging, assisted reproductive technology

\section{INTRODUCTION}

Infertility is of great medical importance and produces relevant socioeconomic impact, as it affects more than 186 million people worldwide. Factors directly related to this condition range from female age and previous illnesses to the unwanted period of inability to conceive (Jacobson et al., 2018).

One of the most used methods in high complexity assisted reproduction is intracytoplasmic sperm injection (ICSI), which has become a viable option with high chances of success for patients seeking conception. The level of anti-Müllerian hormone (AMH) has become an important element in the initial investigation of female patients and is of great importance throughout the process (Jacobson et al., 2018). AMH is a glycoprotein produced by granulosa cells in primary, preantral and small antral follicles, and its clinical applicability has been demonstrated in several studies (Ebner et al., 2006; La Marca \& Volpe, 2006; Gomez et al., 2016). In the literature, there is strong evidence that $\mathrm{AMH}$ is a suitable indicator to assess ovarian reserve and predict the probability of achieving pregnancy (Nelson et al., 2009; Peluso et al., 2014; da Silva et al., 2014; Gomez et al., 2016). Ovarian reserve is defined as the number of ovarian follicles that might be available for use in fertilization, representing a woman's fertile ovarian potential (Nelson et al., 2009; Romão \& Navarro, 2013; Peluso et al., 2014; da Silva et al., 2014; Gomez et al., 2016). Thus, the assessment of ovarian reserve assumes an important role in the attempt to estimate reproductive capacity, which needs to be calculated and informed to patients before treatment initiation.

An association has been established between poor ovarian response and decreasing levels of $\mathrm{AMH}$. $\mathrm{AMH}$ levels decrease substantially with age, which consequently leads to considerably lower probabilities of achieving of pregnancy (La Marca \& Volpe, 2006; Visser et al., 2006; Tal \& Seifer, 2017). According to a study published by Khan et al. (2019), AMH levels decrease by about $6 \%$ a year in older women, showing the direct relationship existing between increased female age and declines in follicular supply. However, female age is not an absolute predictor of reproductive capacity (Khan et al., 2019). In this context, AMH appears as an excellent predictor of fertility.

A study developed by the POSEIDON (Patient Oriented Strategies Encompassing Individualize Oocyte Number) group proposed a new stratification in assisted reproduction. In the study, the ideal AMH level used for comparison was $1.2 \mathrm{ng} / \mathrm{mL}$, based on the idea that women with at least this level of AMH might have better outcomes in terms of number of oocytes generated. This assumption was confirmed in the study, which showed an association between $\mathrm{AMH}$ and female age (Humaidan et al., 2016).

Although $\mathrm{AMH}$ is primarily related to the quantity rather than the quality of oocytes, the higher the AMH levels, the greater are the expectations around the availability of oocytes and ultimately embryos for transfer (Anderson et al., 2012).

Patients must be informed at the beginning of treatment about their ovarian reserve and the potential associations with age, so that they develop more realistic expectations about their response to ovulation induction treatment and become aware of the strong relationship between AMH levels and the probability of achieving pregnancy (Nelson et al., 2009; Peluso et al., 2014; da Silva et al., 2014; Gomez et al., 2016). Research in this area is of great importance and consequence, since it may lead to better approaches based on each patient's profile. This study aimed to find whether there is an association between AMH levels, age, and number of retrieved and mature oocytes of Brazilian patients undergoing assisted reproductive technology (ART) treatments. 


\section{MATERIALS AND METHODS}

This descriptive retrospective observational study included about 1,500 electronic medical records of patients treated at an ART clinic in Curitiba, Paraná, Brazil, between July 2012 and April 2019. Patients not submitted to IVF and/or without AMH level records were excluded. The study included women aged 20-50 years of age submitted to IVF diagnosed with fertility issues.

The patients included in the study were divided into groups based on age and AMH level. The AMH cutoff level was $1.2 \mathrm{ng} / \mathrm{mL}$, as described in the POSEIDON study (Humaidan et al., 2016).

The collected data included patient age, start and duration of treatment, diagnosis and reason for infertility, AMH level, number of metaphase II (MII) oocytes retrieved, and IVF outcome. Data points were statistically analyzed based on quantitative, qualitative, partial, absolute, and comparative parameters.

\section{RESULTS}

During the study period, 1,440 patients underwent ART treatment at the clinic. A total of 733 patients aged 2048 years were enrolled (Table 1 ) after inclusion and exclusion criteria were considered. However, ART outcomes were available for only 681 of the 733 patients. Live birth rates after 21 weeks of pregnancy were significantly higher among younger patients (aged 35 years and younger). Older patients were more likely to having no oocytes retrieved $(p=0.0224)$ (Table 2$)$. All other ART outcomes were similar between the groups.

A total of 717 patients were divided into three age groups (age $\leq 35$ years; age between 36 and 39 years; age $\geq 40$ years). Mean AMH levels were significantly different between the groups and ranged from 2.65 to 1.35 $\mathrm{ng} / \mathrm{mL}$ (Table 3).

The mean number of retrieved oocytes was significantly different between the groups and ranged from 9.5 to 5.42 (Table 3 ). The mean number of mature oocytes in the patient groups ranged from 7.14 to 4.58 (Table 3 ). Patients aged $\leq 35$ years had a greater number of mature oocytes when compared to individuals in the other groups. There was no significant difference in the number of mature oocytes in the groups of patients aged 36-39 years and of patients aged $\geq 40$ years.

The correlations between AMH level, age, and number of retrieved and mature oocytes are shown in Table 4. A negative correlation was observed between age and number of retrieved $(r=-0.3354, p<0.0001)$ and mature oocytes $(r=-0.2839, p<0.0001)$. AMH level was negatively correlated with age $(r=-0.3257, p<0.0001)$. Interestingly, AMH level was positively correlated with number of retrieved $(r=0.6702, p<0.0001)$ and mature oocytes $(r=0.5770, p<0.0001)$.

\section{DISCUSSION}

$\mathrm{AMH}$ is a glycoprotein secreted by granulosa cells of developing ovarian follicles (Siddiqui et al., 2019). It is involved in folliculogenesis and reflects the number of primordial follicles (Seifer \& Maclaughlin, 2007; Pellatt et al., 2010; Tobler et al., 2015). AMH is believed to regulate the number of growing follicles and those that will be selected for ovulation. (Peluso et al., 2014). AMH is considered an inhibitor of the early stages of follicular development (La Marca \& Volpe, 2006). This means that AMH has an inhibitory effect on initial follicular recruitment, thus preventing the premature depletion of primordial follicles (Durlinger et al., 1999; 2001; Kedem et al., 2013; 2014; Pankhurst, 2017; Granger \& Tal, 2019). AMH has shown to have a strong influence on ovarian function, especially on follicle growth (Rey et al., 2000; Visser et al., 2006), and has a good correlation with female age, antral follicle count, and ART outcomes (Fanchin et al., 2003; Nikolaou \& GillingSmith, 2004; Nikolaou, 2008; de Vet et al., 2019). These findings have allowed the widespread use of AMH in the field of gynecology, from IVF to the diagnosis of different ovarian diseases (Dewailly \& Laven, 2019; Bedenk et al., 2020).

Ovarian stimulation is an essential step in ART treatments. The administration of exogenous hormones aims at yielding an adequate ovarian response (Broekmans et al., 2014; Balachandren et al., 2020). Ovarian response measured by the number of retrieved oocytes decreases with age due to progressive ovarian reserve reduction (Hansen et al., 2008; Wallace \& Kelsey, 2010). Decreases in ovarian reserve are an important cause of female infertility. Low ovarian response may occur in ART in 10-20\% of cases and increases with age (Grisendi et al., 2019). Therefore, the assessment of ovarian reserve is an extremely important step in IVF cycles with ovarian stimulation, since it allows the identification of patients at risk of low or excessive ovarian response (Alebic et al., 2018; Bedenk et al., 2020). Once it is not possible to directly determine the number of in vivo follicles, indirect measurements of the ovarian reserve can be made through biochemical and ultrasound markers (Broekmans et al., 2006). AMH is considered the most sensitive marker for ovarian reserve. AMH offers an accurate, direct measurement of the ovarian follicle pool, and can predict the ovarian response and the number of retrieved oocytes from follicular aspiration (Grisendi et al., 2019). AMH concentration assessment offers advantages over other markers such as baseline FSH and antral follicle count, since it is not limited to one phase of the menstrual cycle, does not introduce interobserver variation, and is quite reliable, although there is no internationally standardized trial (Fleming et al., 2015; Grossman et al., 2017; Tal \& Seifer, 2017; Granger \& Tal, 2019; Maged et al., 2020).

\begin{tabular}{|l|c|c|}
\hline Table 1. Diagnosis of patients seen at assisted human reproduction clinic Conceber during the years 2012 and 2019. \\
\hline Diagnosis & Patients (n) & Prevalence \\
\hline Anatomical changes & 52 & $7.09 \%$ \\
\hline Endocrine changes & 37 & $5.05 \%$ \\
\hline Endometriosis & 36 & $4.91 \%$ \\
\hline Male factor & 122 & $16.64 \%$ \\
\hline Ovarian insufficiency & 374 & $51.02 \%$ \\
\hline Idiopathic & 112 & $15.29 \%$ \\
\hline Total & 733 & $100 \%$ \\
\hline
\end{tabular}


Table 2. Outcomes per age group of assisted reproductive technology treatments of patients seen at Conceber Clinic in 2012-2019.

\begin{tabular}{|c|c|c|c|c|}
\hline Outcomes of ART treatment & Up to 35 years & $36-39$ years & Over 40 years & $p$ value \\
\hline Biochemical pregnancy & $48.39 \%(15)$ & $29.03 \%(9)$ & $22.58 \%(7)$ & 0.1869 \\
\hline Complete fertilization failure & $31.71 \%(13)$ & $21.95 \%(9)$ & $46.34 \%(19)$ & 0.1567 \\
\hline Live births ( $>21$ weeks) & $61.21 \% \mathrm{~A}(71)$ & $25.86 \% B(30)$ & $12.93 \% \mathrm{C}(15)$ & $<0.0001 *$ \\
\hline Abnormal/no embryo development & $17.65 \%(9)$ & $41.18 \%(21)$ & $41.18 \%(21)$ & 0.0594 \\
\hline Absence of mature oocytes & $21.43 \%(3)$ & $21.43 \%(3)$ & $57.14 \%(8)$ & 0.1677 \\
\hline Absence of retrieved oocytes & $17.14 \% \mathrm{~A}(6)$ & $28.57 \%$ АВ (10) & $54.29 \% \mathrm{~B}(19)$ & $0.0224 *$ \\
\hline Miscarriage (6 to 21 weeks) & $37.5 \%(3)$ & $25 \%(2)$ & $37.5 \%(3)$ & 0.8825 \\
\hline Low ovarian response & $25 \%(2)$ & $25 \%(2)$ & $50 \%(4)$ & 0.6065 \\
\hline Total cryopreservation & $29.53 \%(57)$ & $36.27 \%(70)$ & $34.2 \%(66)$ & 0.5020 \\
\hline Ovarian hyper response & $100 \%(1)$ & $0 \%(0)$ & $0 \%(0)$ & \\
\hline Ectopic pregnancy & $0 \%(0)$ & $100 \%(2)$ & $0 \%(0)$ & \\
\hline Other complications & $75.00 \%(3)$ & $25.00 \%(1)$ & $0 \%$ & 0.3173 \\
\hline Total & 247 & 232 & 202 & \\
\hline
\end{tabular}

*Different capital letters between lines in the same column represent significant differences between groups $(p<0.05)$.

Table 3. AMH levels and number of retrieved and mature oocytes (mean \pm standard error) per study group of patients seen at assisted human reproduction clinic Conceber in 2012-2019.

\begin{tabular}{|l|c|c|c|c|}
\hline Groups & $\begin{array}{c}\text { Patients } \\
(\mathbf{n})\end{array}$ & $\begin{array}{c}\text { AMH level (ng/mL) } \\
\text { (Mean } \pm \text { SE) }\end{array}$ & $\begin{array}{c}\text { Total number of } \\
\text { retrieved oocytes } \\
\text { (Mean } \pm \text { SE) }\end{array}$ & $\begin{array}{c}\text { Total number of } \\
\text { mature oocytes } \\
\text { (Mean } \pm \text { SE) }\end{array}$ \\
\hline Up to 35y & 258 & $2.65 \pm 0.16^{\mathrm{A}}$ & $9.5 \pm 0.4^{\mathrm{A}}$ & $7.14 \pm 0.4^{\mathrm{A}}$ \\
\hline $36-39 y$ & 251 & $1.75 \pm 0.1^{\mathrm{B}}$ & $7.17 \pm 0.34^{\mathrm{B}}$ & $5.33^{\mathrm{B}} \pm 0.34^{\mathrm{B}}$ \\
\hline Over 40y & 208 & $1.35 \pm 0.12^{\mathrm{C}}$ & $5.42 \pm 0.36^{\mathrm{C}}$ & $4.58 \pm 0.36^{\mathrm{B}}$ \\
\hline
\end{tabular}

Different capital letters between lines in the same column represent significant differences between groups $(p<0.05)$.

Table 4. Correlations ( $r$ ) and significance level $(p)$ between measured response variables.

\begin{tabular}{|l|c|c|c|}
\hline & Retrieved oocyte & Mature oocyte & Age \\
\hline AMH & $\begin{array}{c}0.6702 \\
(<0.0001)\end{array}$ & $\begin{array}{c}0.5770 \\
(<0.0001)\end{array}$ & $\begin{array}{c}-0.3257 \\
(<0.0001)\end{array}$ \\
\hline Age & $\begin{array}{c}-0.3354 \\
(<0.0001)\end{array}$ & $\begin{array}{c}-0.2839 \\
(<0.0001)\end{array}$ & 1.00 \\
\hline
\end{tabular}

In 2012, the American Society of Reproductive Medicine (ASRM) concluded that AMH was a useful tool for predicting ovarian reserve in patients undergoing IVF treatments, as well as for women at risk for decreased ovarian reserve (Gianaroli et al., 2012). The present study showed that AMH levels decrease significantly with age $(p<0.001)$. The negative correlation observed in the present study between $\mathrm{AMH}$ and age had been reported in the literature. (Nardo et al., 2007; Bentzen et al., 2013; Keane et al., 2017; Loy et al., 2017; Massarotti et al., 2020). This result was expected, since AMH represents the pool of oocytes existing in the ovary (Nikolaou, 2008; Iliodromiti et al., 2014). van Rooij et al. (2004) followed 81 patients aged 26 to 45 years for four years. All patients had regular menstrual cycles. Patients who subsequently developed irregular cycles had lower AMH levels than women with regular cycles $(0.3$ and $1.7 \mathrm{ng} / \mathrm{mL}$, respectively, $p<0.001)$. Hansen et al. (2008) observed that AMH levels were significantly higher in women of reproductive age when compared to perimenopausal women. Fatima et al. (2020) described similar results in a study that looked into the differences in AMH levels in different age groups. The authors reported a significant difference in AMH levels between the studied groups. According to Gomez et al. (2016), serum AMH levels decrease annually by approximately $0.384 \mu \mathrm{g} / \mathrm{L}$. In addition, the levels of this hormone are related to the number of oocytes available in the patient. A study by Steiner et al. (2011) evaluated several candidate molecules for markers to predict fertility, including $\mathrm{FSH}$, estradiol, $\mathrm{AMH}$, and inhibin B (plasma levels) and FSH and estrone-3-glucuronide (E3G) in the urine of patients. This study included women aged 30-44 years and showed that only AMH was significantly associated with natural fertility. Some authors believe that the decreases seen in AMH levels with aging may be accelerated due to premature ovarian failure and exposure to gonadotoxic chemotherapy (Méduri et al., 2007; Dólleman et al., 2014; Dunlop \& Anderson, 2015).

According to Fatima et al. (2020), AMH reflects the ovarian reserve and is a predictor of success for several ART treatments. In patients undergoing ART therapies, 
serum AMH is the best endocrine indicator of follicular response to ovarian stimulation compared to other commonly used markers, such as FSH, estradiol, inhibin B, and patient age alone (Arce et al., 2014; Hawkins Bressler \& Steiner, 2018). Compared to FSH, AMH seems to be more strongly associated with age (van Rooij et al., 2005; de Vet et al., 2019); in addition, AMH levels decrease before increases in FSH can be detected (de Vet et al., 2019). Therefore, serum AMH has been considered a more sensitive marker of ovarian reserve than FSH. Although serum AMH levels are controversial for the clinical pregnancy rate in ART, this assessment is still useful to verify the ovarian response to stimulation and to better adjust treatments for patients (Dewailly \& Laven, 2019). Age and serum AMH seem to be independent predictors of ovarian reserve and ovarian stimulation outcome in infertile women (Scheffer et al., 2018).

According to the ASRM and the European Society for Human Reproduction and Embryology (ESHRE), AMH has the best sensitivity and specificity for measuring ovarian response to controlled ovarian hyperstimulation (Gianaroli et al., 2012). A study conducted by Daney de Marcillac et al. (2017) found that patients with normal serum AMH levels had better ovarian stimulation, lower cancellation rates, greater numbers of recovered oocytes after follicular puncture, and higher pregnancy rates. The authors also found that patients with low AMH levels had fewer oocytes retrieved. A study by Melado Vidales et al. (2017) showed that AMH levels measured during IVF predicted patient ovarian response during the days with follicular growth. The results of the present study support the literature (Fleming et al., 2006; Nelson et al., 2007; Granger \& Tal, 2019; Zhang et al., 2019), since patients with higher serum AMH levels showed a significant positive correlation with the total number of retrieved oocytes after follicular puncture. Our data demonstrated that AMH might help predict the number of oocytes produced.

The present study also demonstrated a significant positive correlation between serum AMH and number of mature oocytes. Other authors have suggested that higher serum AMH levels might indicate better oocyte quality, including maturation capacity (Ebner et al., 2006; Gomez et al., 2016; Borges et al., 2017). Although a correlation between embryo quality and chance of blastocyst formation had not been observed, AMH levels were correlated with oocyte quality. In the present study, a significant negative correlation was observed between patient age and number of mature oocytes. AMH levels ranged from $1.35 \pm 0.2$ to $2.65 \pm 0.16 \mathrm{ng} / \mathrm{mL}$. Although AMH levels and number of retrieved oocytes were higher in patients aged $36-39$ years than in individuals aged $>40$ years, the number of mature oocytes did not differ between these individuals. However, both groups had fewer mature oocytes than patients aged $\leq 35$ years. This finding may be related with the median AMH levels seen in the individuals included in this study and explained by the fact that AMH is secreted only by the granulosa cells of preantral follicles and small antral follicles (Maged et al., 2020). The mean serum AMH level was approximately $4 \mathrm{ng} / \mathrm{mL}$ in young women with good ovarian reserve. However, recently, La Marca et al. (2016) described cases with levels below $1 \mathrm{ng} / \mathrm{mL}$ and low ovarian response, and levels above $3 \mathrm{ng} / \mathrm{mL}$ and high response. According to Ebner et al. (2006), oocytes obtained from patients with an intermediate AMH level (between 1.66 and $4.52 \mathrm{ng} / \mathrm{mL}$ ) have better morphology. For Tal \& Seifer (2017), the AMH reference values are age-appropriate and do not refer to a general population of women, regardless of age. These authors considered lower limits of serum AMH of $0.5 \mathrm{ng} / \mathrm{mL}$ for women aged 45 years, $1 \mathrm{ng} / \mathrm{mL}$ for women aged 40 years, $1.5 \mathrm{ng} / \mathrm{mL}$ for women aged 35 years, $2.5 \mathrm{ng} / \mathrm{mL}$ for women aged 30 years, and $3 \mathrm{ng} / \mathrm{mL}$ for women aged 25 years. However, it is important to consider that the ESHRE consensus criteria considered AMH levels $<0.5-1.1 \mathrm{ng} / \mathrm{mL}$ as indication of low ovarian reserve (Ferraretti et al., 2011). To date, several limits have been suggested for $\mathrm{AMH}$ in predicting ovarian response to stimulation. However, there is no uniform agreement due to differences in protocols and populations and $\mathrm{AMH}$ test kits (Shahrokhi et al., 2018). This means that AMH level results should be used and interpreted with caution.

Patient age is an important factor linked to oocyte quality in IVF cycles. The lower chance of older patients becoming pregnant after IVF is due to poorer response to ovarian stimulation, worse oocyte quality, and higher aneuploidy rates (Franasiak et al., 2014; Scheffer et al., $2017)$. Our study showed that the number of retrieved oocytes decreased with patient age $(<0.001)$. Age was negatively correlated with the number of retrieved and mature oocytes. As age advances, an inhibitory effect of AMH on the recruitment of follicles becomes possible (Nelson et al., 2009; Pacheco et al., 2017).

Regarding the quality of oocytes, some authors believe that a low ovarian reserve might increase the chances of aneuploidy. Several studies suggest that low ovarian reserve and the consequent absence of adequate follicles for selection increase the likelihood of aneuploid oocytes being harvested (Warburton, 1989; Haadsma et al., 2010; Rosen et al., 2011; Grande et al., 2015; Pankhurst, 2017). Total chromosomal non-disjunction and early separation of sister chromatids are correlated with maternal aging. Changes in sister chromatids cohesion may be a causal mechanism that predisposes premature separation and consequently non-disjunction during meiosis. In addition, the asymmetry of the female meiotic division might favor the non-random segregation of chromosomes and chromatids (Johnson et al., 2007; Scheffer et al., 2018). Oocyte aging causes increased damage to mitochondrial DNA and decreased oxidative phosphorylation and ATP production. Mitochondrial mutations in follicular cells around the oocyte have been correlated with maternal age, suggesting that oxidative phosphorylation in the follicle is compromised (Smeenk et al., 2007). Aneuploid oocyte rates increase with age. Women under 35 years of age have an embryo aneuploidy rate of $53 \%$ in IVF, while older women present significantly higher aneuploidy rates ( $74 \%$ in patients aged $41-42$ years and $93 \%$ in women aged $42+$ years) (Harton et al., 2013).

AMH can be considered an indirect way of measuring the number of preantral and primordial follicles. It is a useful predictor for the pool of follicles that will be ready for final development in the next 3-5 months. Since the number of "selectable" follicles remains approximately constant over time, it can be speculated that AMH levels might predict response to controlled ovarian stimulation. On the other hand, since the number of follicles ready to mature depends on the primordial follicle pool, AMH can be used safely to estimate the ovarian reserve. To date, there is no direct method (except for histological evaluation) for measuring the size of the primordial follicle pool (Gasca et al., 2007). However, little is known about the relationship between variations in AMH levels and the qualitative results of ART treatments (implantation, pregnancy, and birth). A recent Brazilian study showed that age negatively affected embryo or blastocyst quality at day 3 (women aged $35+$ years) in subjects with low serum AMH levels $(<1 \mathrm{ng} / \mathrm{mL})$ and antral follicle counts of less than seven (Scheffer et al., 2021).

Our data showed that a Brazilian cohort with advanced age had significant decreases in AMH levels and low numbers of retrieved and mature oocytes. However, we found no significant differences in the number of retrieved and mature oocytes between patients aged 36 years or older. 
We also found a positive correlation between serum $\mathrm{AMH}$ levels and the total number of retrieved and mature oocytes. Although this study did not report new data compared to the literature, to our knowledge this is the largest study enrolling Brazilian IVF patients in which correlations between AMH levels, age, and total number of oocytes and mature oocytes from stimulated cycles were described.

\section{CONFLICT OF INTEREST}

The authors have no conflict of interest to declare.

\section{Corresponding author:}

Alessandro Schuffner

Conceber Centro de Medicina Reprodutiva

Curitiba, Paraná, Brazil.

E-mail: alessandro@clinicaconceber.com.br

\section{REFERENCES}

Alebic MŠ, Stojanovic N, Dewailly D. Discordance between serum anti-Müllerian hormone concentrations and antral follicle counts: not only technical issues. Hum Reprod. 2018;33:1141-8. PMID: 29688494 DOI: 10.1093/humrep/dey098

Anderson RA, Nelson SM, Wallace WH. Measuring anti-Müllerian hormone for the assessment of ovarian reserve: when and for whom is it indicated? Maturitas. 2012;71:28-33. PMID: 22119275 DOI: $10.1016 /$ j.maturitas. 2011.11 .008

Arce JC, Andersen AN, Fernández-Sánchez M, Visnova $H$, Bosch E, García-Velasco JA, Barri P, de Sutter P, Klein BM, Fauser BC. Ovarian response to recombinant human follicle-stimulating hormone: a randomized, antimüllerian hormone-stratified, dose-response trial in women undergoing in vitro fertilization/intracytoplasmic sperm injection. Fertil Steril. 2014;102:1633-40.e5. PMID: 25256937 DOI: 10.1016/j.fertnstert.2014.08.013

Balachandren N, Salman M, Diu NL, Schwab S, Rajah K, Mavrelos D. Ovarian reserve as a predictor of cumulative live birth. Eur J Obstet Gynecol Reprod Biol. 2020;252:2737. PMID: 32645642 DOI: 10.1016/j.ejogrb.2020.06.063

Bedenk J, Vrtačnik-Bokal E, Virant-Klun I. The role of anti-Müllerian hormone (AMH) in ovarian disease and infertility. J Assist Reprod Genet. 2020;37:89-100. PMID: 31755000 DOI: $10.1007 / \mathrm{s} 10815-019-01622-7$

Bentzen JG, Forman JL, Johannsen TH, Pinborg A, Larsen EC, Andersen AN. Ovarian antral follicle subclasses and anti-Müllerian hormone during normal reproductive aging. J Clin Endocrinol Metab. 2013;98:1602-11. PMID: 23463653 DOI: $10.1210 / j c .2012-1829$

Borges E, Braga DPAF, Setti A, Figueira RC, Iaconelli A Jr. The predictive value of serum concentrations of anti-Müllerian hormone for oocyte quality, fertilization, and implantation. JBRA Assist Reprod. 2017;21:176-82. PMID: 28837024 DOI: $10.5935 / 1518-0557.20170035$

Broekmans FJ, Kwee J, Hendriks DJ, Mol BW, Lambalk CB. A systematic review of tests predicting ovarian reserve and IVF outcome. Hum Reprod Update. 2006;12:685-718. PMID: 16891297 DOI: 10.1093/humupd/dmI034
Broekmans FJ, Verweij PJ, Eijkemans MJ, Mannaerts BM, Witjes $\mathrm{H}$. Prognostic models for high and low ovarian responses in controlled ovarian stimulation using a $\mathrm{GnRH}$ antagonist protocol. Hum Reprod. 2014;29:1688-97. PMID: 24903202 DOI: 10.1093/humrep/deu090

da Silva GM, Diniz AL, Bernardino Neto M, Marcolini $T$, Perillo LC, Pires Wde P, Pessoa SM. Number of antral follicles and the success of in vitro fertilization: a multivariate analysis. Rev Bras Ginecol Obstet. 2014;36:473-9. PMID: 25317827 DOI: $10.1590 /$ S0100-720320140005046

Daney de Marcillac F, Pinton A, Guillaume A, Sagot P, Pirrello $\mathrm{O}$, Rongieres $\mathrm{C}$. What are the likely IVF/ICSI outcomes if there is a discrepancy between serum AMH and FSH levels? A multicenter retrospective study. J Gynecol Obstet Hum Reprod. 2017;46:629-35. PMID: 28843783 DOI: $10.1016 /$ j.jogoh.2017.08.001

de Vet A, Laven JSE, de Jong FH, Themmen APN, Fauser BCJM. Reprint of: Antimüllerian hormone serum levels: a putative marker for ovarian aging. Fertil Steril. 2019;112:e183-e8. PMID: 31623731 DOI: 10.1016/j. fertnstert.2019.08.088

Dewailly D, Laven J. AMH as the primary marker for fertility. Eur J Endocrinol. 2019;181:D45-D51. PMID: 31398713 DOI: $0.1530 / E J E-19-0373$

Dólleman M, Depmann M, Eijkemans MJ, Heimensem J, Broer SL, van der Stroom EM, Laven JS, Van Rooij IA, Scheffer GJ, Peeters PH, van der Schouw YT, Lambalk CB, Broekmans FJ. Anti-Müllerian hormone is a more accurate predictor of individual time to menopause than mother's age at menopause. Hum Reprod. 2014;29:584-91. PMID: 24435779 DOI: $10.1093 /$ humrep/det446

Dunlop CE, Anderson RA. Uses of anti-Müllerian hormone (AMH) measurement before and after cancer treatment in women. Maturitas. 2015;80:245-50. PMID: 25596814 DOI: $10.1016 /$ j.maturitas.2014.12.005

Durlinger AL, Kramer $\mathrm{P}$, Karels $\mathrm{B}$, de Jong $\mathrm{FH}$, Uilenbroek JT, Grootegoed JA, Themmen AP. Control of primordial follicle recruitment by anti-Müllerian hormone in the mouse ovary. Endocrinology. 1999;140:5789-96. PMID: 10579345 DOI: 10.1210/endo.140.12.7204

Durlinger AL, Gruijters MJ, Kramer P, Karels B, Kumar TR, Matzuk MM, Rose UM, de Jong FH, Uilenbroek JT, Grootegoed JA, Themmen AP. Anti-Müllerian hormone attenuates the effects of FSH on follicle development in the mouse ovary. Endocrinology. 2001;142:4891-9. PMID: 11606457 DOI: $10.1210 /$ endo.142.11.8486

Ebner T, Sommergruber M, Moser M, Shebl O, Schreier-Lechner $E$, Tews G. Basal level of anti-Müllerian hormone is associated with oocyte quality in stimulated cycles. Hum Reprod. 2006;21:2022-6. PMID: 16679324 DOI: 10.1093/ humrep/del127

Fanchin R, Schonäuer LM, Righini C, Guibourdenche J, Frydman R, Taieb J. Serum anti-Müllerian hormone is more strongly related to ovarian follicular status than serum inhibin $B$, estradiol, FSH and LH on day 3. Hum Reprod. 2003;18:323-7. PMID: 12571168 DOI: $10.1093 /$ humrep/deg042 
Fatima S, Naqvi Q, Tauseef A, Qamar M, Khan QU, Akram T, Saeed M. Correlation of Serum Anti-Müllerian Hormone with Ovarian Follicle Output Rate in Infertile Females: A Clomiphene Citrate Challenge Test. Cureus. 2020;12:e8032. PMID: 32528768 DOI: 10.7759/cureus.8032

Ferraretti AP, La Marca A, Fauser BC, Tarlatzis B, Nargund G, Gianaroli L; ESHRE working group on Poor Ovarian Response Definition. ESHRE consensus on the definition of 'poor response' to ovarian stimulation for in vitro fertilization: the Bologna criteria. Hum Reprod. 2011;26:1616-24. PMID: 21505041 DOI: 10.1093/humrep/der092

Fleming R, Deshpande N, Traynor I, Yates RW. Dynamics of FSH-induced follicular growth in subfertile women: relationship with age, insulin resistance, oocyte yield and anti-Müllerian hormone. Hum Reprod. 2006;21:1436-41. PMID: 16439501 DOI: 10.1093/humrep/dei499

Fleming R, Seifer DB, Frattarelli JL, Ruman J. Assessing ovarian response: antral follicle count versus anti-Müllerian hormone. Reprod Biomed Online. 2015;31:486-96. PMID: 26283017 DOI: 10.1016/j.rbmo.2015.06.015

Franasiak JM, Forman EJ, Hong $\mathrm{KH}$, Werner MD, Upham KM, Treff NR, Scott RT Jr. The nature of aneuploidy with increasing age of the female partner: a review of 15,169 consecutive trophectoderm biopsies evaluated with comprehensive chromosomal screening. Fertil Steril. 2014;101:656-63.e1. PMID: 24355045 DOI: 10.1016/j. fertnstert.2013.11.004

Gasca S, Pellestor F, Assou S, Loup V, Anahory T, Dechaud $\mathrm{H}$, De Vos J, Hamamah S. Identifying new human oocyte marker genes: a microarray approach. Reprod Biomed Online. 2007;14:175-83. PMID: 17298719 DOI: 10.1016/ S1472-6483(10)60785-7

Gianaroli L, Racowsky C, Geraedts J, Cedars M, Makrigiannakis A, Lobo R. Best practices of ASRM and ESHRE: a journey through reproductive medicine. Hum Reprod. 2012;27:3365-79. PMID: 23097354 DOI: 10.1093/humrep/des338

Gomez R, Schorsch M, Hahn T, Henke A, Hoffmann I, Seufert R, Skala C. The influence of AMH on IVF success. Arch Gynecol Obstet. 2016;293:667-73. PMID: 26449238 DOI: $10.1007 / \mathrm{s} 00404-015-3901-0$

Grande M, Borobio V, Bennasar M, Stergiotou I, Mercadé I, Masoller N, Peñarrubia J, Borrell A. Role of ovarian reserve markers, antimüllerian hormone and antral follicle count, as aneuploidy markers in ongoing pregnancies and miscarriages. Fertil Steril. 2015;103:1221-7.e2. PMID: 25796318 DOI: 10.1016/j.fertnstert.2015.02.022

Granger E, Tal R. Anti-Müllerian Hormone and Its Predictive Utility in Assisted Reproductive Technologies Outcomes. Clin Obstet Gynecol. 2019;62:238-56. PMID: 30994481 DOI: $10.1097 / G R F .0000000000000436$

Grisendi V, Mastellari E, La Marca A. Ovarian Reserve Markers to Identify Poor Responders in the Context of Poseidon Classification. Front Endocrinol (Lausanne). 2019;10:281. PMID: 31139145 DOI: 10.3389/fendo.2019.00281
Grossman LC, Safier LZ, Kline MD, Chan CW, Lobo RA, Sauer MV, Douglas NC. Utility of Ovarian Reserve Screening with Anti-Müllerian Hormone for Reproductive Age Women Deferring Pregnancy. J Womens Health (Larchmt). 2017;26:345-51. PMID: 27906603 DOI: 10.1089/jwh.2016.5842

Haadsma ML, Mooij TM, Groen $\mathrm{H}$, Burger CW, Lambalk CB, Broekmans FJ, van Leeuwen FE, Bouman K, Hoek A; OMEGA Project Group. A reduced size of the ovarian follicle pool is associated with an increased risk of a trisomic pregnancy in IVF-treated women. Hum Reprod. 2010;25:552-8. PMID: 19920066 DOI: 10.1093/humrep/dep404

Hansen KR, Knowlton NS, Thyer AC, Charleston JS, Soules $M R$, Klein NA. A new model of reproductive aging: the decline in ovarian non-growing follicle number from birth to menopause. Hum Reprod. 2008;23:699-708. PMID: 18192670 DOI: $10.1093 /$ humrep/dem408

Harton GL, Munné S, Surrey M, Grifo J, Kaplan B, McCulloh DH, Griffin DK, Wells D; PGD Practitioners Group. Diminished effect of maternal age on implantation after preimplantation genetic diagnosis with array comparative genomic hybridization. Fertil Steril. 2013;100:1695-703. PMID: 24034939 DOI: 10.1016/j.fertnstert.2013.07.2002

Hawkins Bressler L, Steiner A. Anti-Müllerian hormone as a predictor of reproductive potential. Curr Opin Endocrinol Diabetes Obes. 2018;25:385-90. PMID: 30299431 DOI: 10.1097/MED.0000000000000440

Humaidan P, Alviggi C, Fischer R, Esteves SC. The novel POSEIDON stratification of 'Low prognosis patients in Assisted Reproductive Technology' and its proposed marker of successful outcome. F1000Res. 2016;5:2911. PMID: 28232864 DOI: 10.12688/f1000research.10382.1

Iliodromiti S, Kelsey TW, Wu O, Anderson RA, Nelson SM. The predictive accuracy of anti-Müllerian hormone for live birth after assisted conception: a systematic review and meta-analysis of the literature. Hum Reprod Update. 2014;20:560-70. PMID: 24532220 DOI: 10.1093/humupd/dmu003

Jacobson MH, Chin HB, Mertens AC, Spencer JB, Fothergill A, Howards PP. "Research on Infertility: Definition Makes a Difference" Revisited. Am J Epidemiol. 2018;187:337-46. PMID: 28633422 DOI: 10.1093/aje/kw×240

Johnson MT, Freeman EA, Gardner DK, Hunt PA. Oxidative metabolism of pyruvate is required for meiotic maturation of murine oocytes in vivo. Biol Reprod. 2007;77:2-8. PMID: 17314311 DOI: 10.1095/biolreprod.106.059899

Keane K, Cruzat VF, Wagle S, Chaudhary N, Newsholme $P$, Yovich J. Specific ranges of anti-Müllerian hormone and antral follicle count correlate to provide a prognostic indicator for IVF outcome. Reprod Biol. 2017;17:51-9. PMID: 28132758 DOI: $10.1016 /$ j.repbio.2016.12.002

Kedem A, Hourvitz A, Yung Y, Shalev L, Yerushalmi GM, Kanety $\mathrm{H}$, Hanochi M, Maman E. Anti-Müllerian hormone $(\mathrm{AMH})$ downregulation in late antral stages is impaired in PCOS patients. A study in normo-ovulatory and PCOS patients undergoing in vitro maturation (IVM) treatments. Gynecol Endocrinol. 2013;29:651-6. PMID: 23772776 DOI: $10.3109 / 09513590.2013 .798279$ 
Kedem A, Yung Y, Yerushalmi GM, Haas J, Maman E, Hanochi M, Hemi R, Orvieto R, Dor J, Hourvitz A. Anti Müllerian Hormone (AMH) level and expression in mural and cumulus cells in relation to age. J Ovarian Res. 2014;7:113. PMID: 25500128 DOI: 10.1186/s13048-014-0113-3

Khan HL, Bhatti S, Suhail S, Gul R, Awais A, Hamayun $H$, Enver F, Abbas S, Hassan Z, Nisar R, Sardar S, Asif W. Antral follicle count (AFC) and serum anti-Müllerian hormone $(\mathrm{AMH})$ are the predictors of natural fecundability have similar trends irrespective of fertility status and menstrual characteristics among fertile and infertile women below the age of 40 years. Reprod Biol Endocrinol. 2019;17:20. PMID: 30744650 DOI: 10.1186/s12958-019-0464-0

La Marca A, Volpe A. Anti-Müllerian hormone (AMH) in female reproduction: is measurement of circulating $A M H$ a useful tool? Clin Endocrinol. 2006;64:603-10. PMID: 16712660 DOI: $10.1111 /$ j.1365-2265.2006.02533.x

La Marca A, Ferraretti AP, Palermo R, Ubaldi FM. The use of ovarian reserve markers in IVF clinical practice: a national consensus. Gynecol Endocrinol. 2016;32:1-5. PMID: 26531067 DOI: $10.3109 / 09513590.2015 .1102879$

Loy SL, Cheung YB, Fortier MV, Ong CL, Tan $\mathrm{HH}$, Nadarajah $\mathrm{S}$, Chan JKY, Viardot-Foucault V. Age-related nomograms for antral follicle count and anti-Müllerian hormone for subfertile Chinese women in Singapore. PLoS One. 2017;12:e0189830. PMID: 29240820 DOI: 10.1371/journal.pone.0189830

Maged AM, Nabil H, Dieb AS, Essam A, Ibrahim S, Deeb W, Fahmy RM. Prediction of metaphase II oocytes according to different levels of serum AMH in poor responders using the antagonist protocol during ICSI: a cohort study. Gynecol Endocrinol. 2020;36:728-33. PMID: 31870186 DOI: $10.1080 / 09513590.2019 .1706081$

Massarotti C, La Pica V, Sozzi F, Scaruffi P, Remorgida V, Anserini $P$. Influence of age on response to controlled ovarian stimulation in women with low levels of serum anti-Müllerian hormone. Gynecol Endocrinol. 2020;36:1074-8. PMID: 32148116 DOI: $10.1080 / 09513590.2020 .1737668$

Méduri G, Massin N, Guibourdenche J, Bachelot A, Fiori O, Kuttenn F, Misrahi M, Touraine P. Serum anti-Müllerian hormone expression in women with premature ovarian failure. Hum Reprod. 2007;22:117-23. PMID: 16954410 DOI: $10.1093 /$ humrep/del346

Melado Vidales L, Fernández-Nistal A, Martínez Fernández V, Verdú Merino V, Bruna Catalán I, Bajo Arenas JM. Anti-Müllerian hormone dynamics during GNRH-antagonist short protocol for IVF/ICSI in women with varying ovarian reserve levels. Minerva Ginecol. 2017;69:128-34. PMID: 27310675 DOI: $10.23736 / S 0026-4784.16 .03951-4$

Nardo LG, Christodoulou D, Gould D, Roberts SA, Fitzgerald CT, Laing I. Anti-Müllerian hormone levels and antral follicle count in women enrolled in in vitro fertilization cycles: relationship to lifestyle factors, chronological age and reproductive history. Gynecol Endocrinol. 2007;23:48693. PMID: 17852428 DOI: $10.1080 / 09513590701532815$
Nelson SM, Yates RW, Fleming R. Serum anti-Müllerian hormone and FSH: prediction of live birth and extremes of response in stimulated cycles--implications for individualization of therapy. Hum Reprod. 2007;22:2414-21. PMID: 17636277 DOI: 10.1093/humrep/dem204

Nelson SM, Yates RW, Lyall H, Jamieson M, Traynor I, Gaudoin M, Mitchell P, Ambrose P, Fleming R. Anti-Müllerian hormone-based approach to controlled ovarian stimulation for assisted conception. Hum Reprod. 2009;24:86775. PMID: 19136673 DOI: 10.1093/humrep/den480

Nikolaou D. How old are your eggs? Curr Opin Obstet Gynecol. 2008;20:540-4. PMID: 18989128 DOI: 10.1097/ GCO.0b013e328317c755

Nikolaou D, Gilling-Smith C. Early ovarian ageing: are women with polycystic ovaries protected? Hum Reprod. 2004;19:2175-9. PMID: 15256506 DOI: $10.1093 /$ humrep/deh419

Pacheco A, Cruz M, Garcia Velasco JA. Impact of very low anti-Müllerian hormone on pregnancy success. Curr Opin Obstet Gynecol. 2017;29:131-5. PMID: 28212156 DOI: $10.1097 /$ GCO.0000000000000354

Pankhurst MW. A putative role for anti-Müllerian hormone $(\mathrm{AMH})$ in optimising ovarian reserve expenditure. J Endocrinol. 2017;233:R1-3. PMID: 28130407 DOI: 10.1530/ JOE-16-0522

Pellatt L, Rice S, Mason HD. Anti-Müllerian hormone and polycystic ovary syndrome: a mountain too high? Reproduction. 2010;139:825-33. PMID: 20207725 DOI: 10.1530/REP-09-0415

Peluso C, Fonseca FL, Rodart IF, Cavalcanti V, Gastaldo G, Christofolini DM, Barbosa CP, Bianco B. AMH: An ovarian reserve biomarker in assisted reproduction. Clin Chim Acta. 2014;437:175-82. PMID: 25086280 DOI: $10.1016 / \mathrm{j}$. cca.2014.07.029

Rey $R$, Sabourin JC, Venara M, Long WQ, Jaubert F, Zeller WP, Duvillard P, Chemes H, Bidart JM. Anti-Müllerian hormone is a specific marker of sertoli- and granulosa-cell origin in gonadal tumors. Hum Pathol. 2000;31:1202-8. PMID: 11070112 DOI: 10.1053/hupa.2000.18498

Romão GS, Navarro PA. Clinical use for anti-Müllerian hormone in gynecology. Rev Bras Ginecol Obstet. 2013;35:136-40. PMID: 23538473

Rosen MP, Johnstone E, Addauan-Andersen C, Cedars MI. A lower antral follicle count is associated with infertility. Fertil Steril. 2011;95:1950-4, 1954.e.1. PMID: 21376313 DOI: 10.1016/j.fertnstert.2011.01.151

Scheffer JB, Scheffer BB, de Carvalho RF, Rodrigues J, Grynberg M, Mendez Lozano DH. Age as A Predictor of Embryo Quality Regardless of The Quantitative Ovarian Response. Int J Fertil Steril. 2017;11:40-6. PMID: 28367304 DOI: $10.22074 /$ ijfs. 2016.4579 
Scheffer JAB, Scheffer B, Scheffer R, Florencio F, Grynberg $M$, Lozano DM. Are age and anti-Müllerian hormone good predictors of ovarian reserve and response in women undergoing IVF? JBRA Assist Reprod. 2018;22:215-20. PMID: 29949322 DOI: 10.5935/1518-0557.20180043

Scheffer JB, Carvalho RF, Aguiar APS, Machado IJM, Franca JB, Lozano DM, Fanchin R. Which ovarian reserve marker relates to embryo quality on day 3 and blastocyst; age, AFC, AMH? JBRA Assist Reprod. 2021;25:109-14. PMID: 32960526 DOI: $10.5935 / 1518-0557.20200060$

Seifer DB, Maclaughlin DT. Müllerian Inhibiting Substance is an ovarian growth factor of emerging clinical significance. Fertil Steril. 2007;88:539-46. PMID: 17559842 DOI: $10.1016 /$ j.fertnstert.2007.02.014

Shahrokhi SZ, Kazerouni F, Ghaffari F. Anti-Müllerian Hormone: genetic and environmental effects. Clin Chim Acta. 2018;476:123-9. PMID: 29175649 DOI: 10.1016/j. cca.2017.11.027

Siddiqui QUA, Anjum S, Zahra F, Yousuf SM. Ovarian reserve parameters and response to controlled ovarian stimulation in infertile patients. Pak J Med Sci. 2019;35:95862. PMID: 31372124 DOI: $10.12669 /$ pjms.35.4.753

Smeenk JM, Sweep FC, Zielhuis GA, Kremer JA, Thomas $\mathrm{CM}$, Braat DD. Antimüllerian hormone predicts ovarian responsiveness, but not embryo quality or pregnancy, after in vitro fertilization or intracyoplasmic sperm injection. Fertil Steril. 2007;87:223-6. PMID: 17081531 DOI: 10.1016/j. fertnstert.2006.06.019

Steiner AZ, Herring AH, Kesner JS, Meadows JW, Stanczyk FZ, Hoberman S, Baird DD. AntiMüllerian hormone as a predictor of natural fecundability in women aged 3042 years. Obstet Gynecol. 2011;117:798-804. PMID: 21422850 DOI: $10.1097 /$ AOG.0b013e3182116bc8
Tal R, Seifer DB. Ovarian reserve testing: a user's guide. Am J Obstet Gynecol. 2017;217:129-40. PMID: 28235465 DOI: $10.1016 /$ j.ajog.2017.02.027

Tobler KJ, Shoham G, Christianson MS, Zhao Y, Leong M, Shoham Z. Use of anti-Müllerian hormone for testing ovarian reserve: a survey of 796 infertility clinics worldwide. J Assist Reprod Genet. 2015;32:1441-8. PMID: 26347341 DOI: $10.1007 / \mathrm{s} 10815-015-0562-7$

van Rooij IA, Tonkelaar I, Broekmans FJ, Looman CW, Scheffer GJ, de Jong FH, Themmen AP, te Velde ER. Anti-Müllerian hormone is a promising predictor for the occurrence of the menopausal transition. Menopause. 2004;11:601-6. PMID: 15545787 DOI: 10.1097/01. GME.0000123642.76105.6E

van Rooij IA, Broekmans FJ, Scheffer GJ, Looman CW, Habbema JD, de Jong $F H$, Fauser $B J$, Themmen AP, te Velde ER. Serum antiMüllerian hormone levels best reflect the reproductive decline with age in normal women with proven fertility: a longitudinal study. Fertil Steril. 2005;83:979-87. PMID: 15820810 DOI: $10.1016 /$ j.fertnstert.2004.11.029

Visser JA, de Jong FH, Laven JS, Themmen AP. Anti-Müllerian hormone: a new marker for ovarian function. Reproduction. 2006;131:1-9. PMID: 16388003 DOI: 10.1530/rep.1.00529

Wallace WH, Kelsey TW. Human ovarian reserve from conception to the menopause. PLoS One. 2010;5:e8772. PMID: 20111701 DOI: 10.1371/journal.pone.0008772

Warburton D. The effect of maternal age on the frequency of trisomy: change in meiosis or in utero selection? Prog Clin Biol Res. 1989;311:165-81. PMID: 2672026

Zhang B, Meng $Y$, Jiang $X$, Liu C, Zhang $H$, Cui $L$, Chen $Z$ J. IVF outcomes of women with discrepancies between age and serum anti-Müllerian hormone levels. Reprod Biol Endocrinol. 2019;17:58. PMID: 31311571 DOI: 10.1186/ s12958-019-0498-3 